\title{
Endoscopic clipping prior to n-butyl-2-cyanoacrylate injection for gastric varices with a large gastrorenal shunt
}

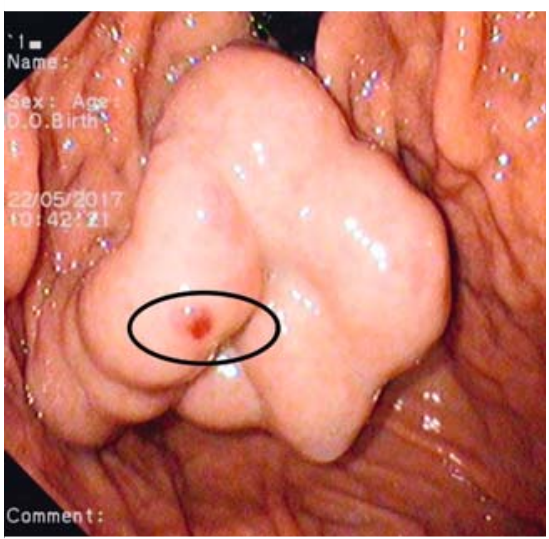

- Fig. 1 Endoscopic view of a huge gastric fundal varix with hemorrhagic spots.

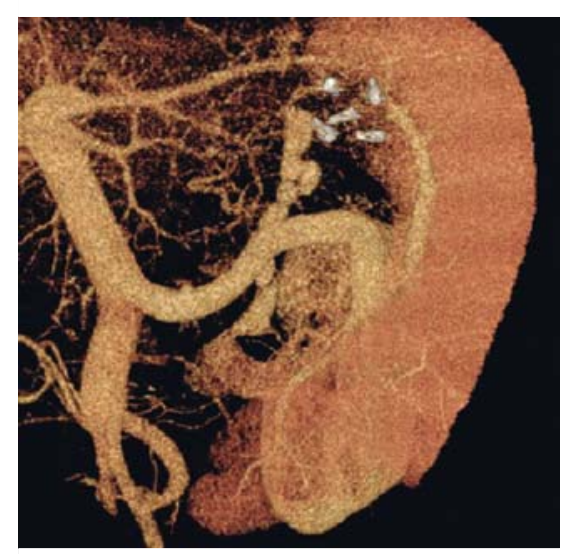

Fig. 4 Follow-up computed tomography scan 2 weeks later showing the blocked gastric varix and gastrorenal shunt.

Gastric variceal obturation with cyanoacrylate has been proven to be an effective treatment for gastric varices with a shunt [1]. However, there may be complications after the treatment, such as systemic embolism [2], which can be severe and even fatal. With the aim of reducing the risk of complications, we here report on the use of endoscopic clipping prior to n-butyl-2-cyanoacrylate injection as a therapy to obliterate gastric varices with a large gastrorenal shunt.

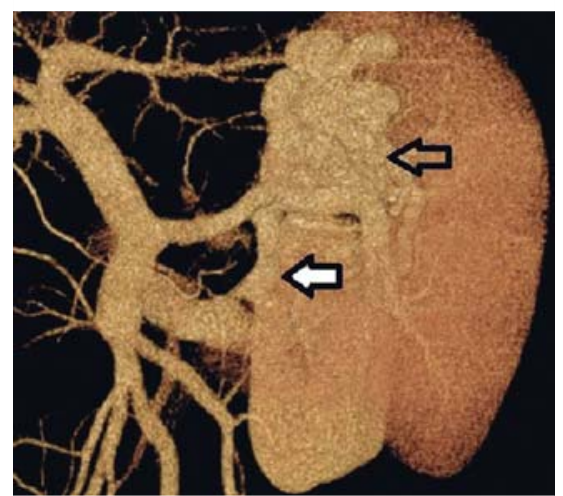

- Fig. 2 Computed tomography scan showing the gastric varix (black arrow) with a large gastrorenal shunt (white arrow).

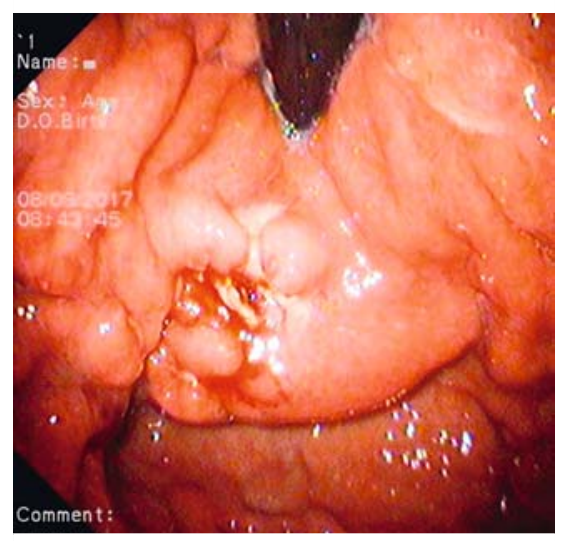

- Fig. 5 View during follow-up endoscopy 4 months later showing an injected ulcer and obliterated varix.

A 56-year-old man was admitted to our department with a diagnosis of esophagogastric variceal hemorrhage and decompensated post-hepatitic cirrhosis. Emergency gastroscopy revealed a huge gastric fundal varix with hemorrhagic spots ( $\triangleright$ Fig. 1 ). The diameter of the gastrorenal shunt was $11.5 \mathrm{~mm}$ on computed tomography (CT) scanning ( $\mathbf{F i g . 2}$ ). Endoscopic treatment was performed immediately. We planned to deploy five clips (Instinct; Cook Medical, Blooming-

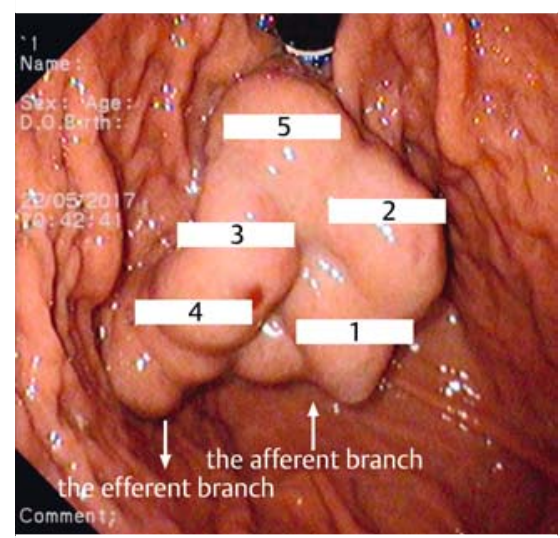

Fig. 3 We planned to deploy five clips on the varix with the order and location of deployment as indicated.

ton, Indiana, USA) on the varix (> Fig. 3 ). Specifically, the first clip was deployed on the afferent branch of the varix. Deployment of the third clip caused the vessel to be broken and a little blood oozed out. A fourth clip was applied on the efferent branch of the varix. Finally, because of the large intravenous cavity on the upper part of the vein, the last clip was placed on the cavity, so as to reduce the volume of cyanoacrylate required.

After the clips had been placed, a "modified Sandwich method” (lauromacrogol, n-butyl-2-cyanoacrylate, and sodium morrhuate) was used to complete the procedure. We injected the mixture on top of the broken point, and the bleeding quickly stopped. Two additional points were injected on each side of the first injection point and then one on the efferent branch until the whole varix had been solidified ( $\nabla$ Video 1 ). A total of 8 $\mathrm{mL}$ n-butyl-2-cyanoacrylate (Histoacryl; B. Braun, Melsungen, Germany), $25 \mathrm{~mL}$ lauromacrogol (Tianyu Pharmaceutical Co. Ltd., Shanxi, China), and $10 \mathrm{~mL}$ sodium morrhuate were used during the procedure. 


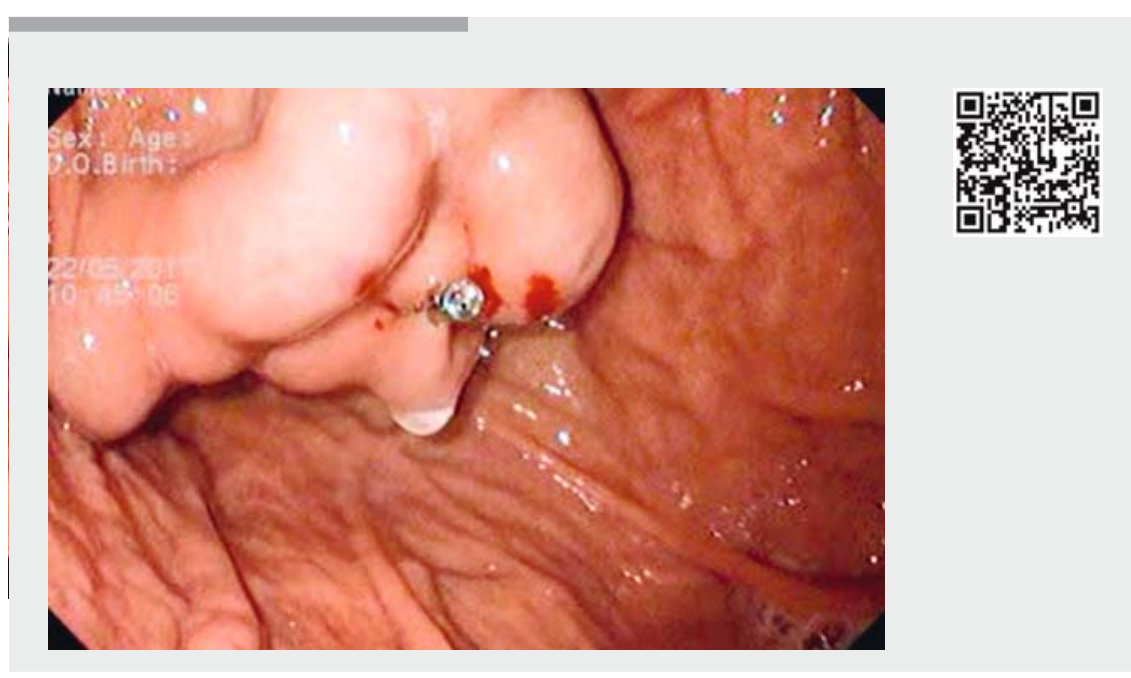

$\checkmark$ Video 1 A gastric varix with large gastrorenal shunt is treated endoscopically with deployment of five clips followed by injection of $8 \mathrm{~mL}$-butyl-2-cyanoacrylate.

A follow-up CT scan 2 weeks later showed the blocked gastric varix and gastrorenal shunt ( $>$ Fig. 4 ). No bleeding or systemic embolism were reported during the 4-month follow-up period ( Fig. 5).

Endoscopy_UCTN_Code_TTT_1AO_2AD

Competing interests

None

\section{The authors}

Huixian $\mathrm{Li}^{1,}$, , Dong Ye ${ }^{2,}$ ", Derun Kong1

1 Department of Gastroenterology, Anhui Geriatric Institute, First Affiliated Hospital of Anhui Medical University, Anhui, China

2 Department of Infectious Diseases, Infectious Diseases Hospital of Handan City, Hebei, China

\section{Corresponding author}

\section{Derun Kong, MD}

Department of Gastroenterology, Anhui Geriatric Institute, First Affiliated Hospital of Anhui Medical University, Jixi Road 218,

Hefei 230022, China

kdr168@163.com

* Joint first authors
[1] Sarin SK, Kumar A. Endoscopic treatment of gastric varices. Clin Liver Dis 2014; 18: $809-$ 827

[2] Irisawa A, Obara K, Sato Y et al. Adherence of cyanoacrylate which leaked from gastric varices to the left renal vein during endoscopic injection sclerotherapy: a histopathologic study. Endoscopy 2000; 32: $804-806$

\section{Bibliography}

DOI https://doi.org/10.1055/s-0043-123822

Published online: 8.2.2018

Endoscopy 2018; 50: E102-E103

(c) Georg Thieme Verlag KG

Stuttgart · New York

ISSN 0013-726X

\section{ENDOSCOPY E-VIDEOS}

https://eref.thieme.de/e-videos

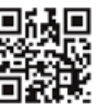

Endoscopy E-Videos is a free access online section, reporting on interesting cases and new techniques in gastroenterological endoscopy. All papers include a high quality video and all contributions are freely accessible online.

This section has its own submission website at

https://mc.manuscriptcentral.com/e-videos 